\title{
Myths and Misconceptions About University Student Volunteering: Development and Perpetuation
}

\author{
Megan Paull ${ }^{1}$ (D) Kirsten Holmes ${ }^{2} \cdot$ Maryam Omari $^{3} \cdot$ Debbie Haski-Leventhal $^{4}$ • \\ Judith MacCallum ${ }^{5} \cdot$ Susan Young $^{6} \cdot$ Rowena Scott $^{1}$
}

Accepted: 17 November 2021 / Published online: 3 January 2022

(C) International Society for Third-Sector Research 2021

\begin{abstract}
This paper examines myths and misconceptions about university student volunteering. Our study explored the experiences of students, host organisations and universities participating in volunteering in Australia, identify good practice, and discover barriers to success. A qualitative approach involved 60 semi-structured interviews with stakeholders. Students were often seen as being energetic, having flexible time and having skills associated with their studies. Some organisations, however, viewed students as unreliable, hard to manage and requiring specific programs. Some hosts were viewed as not valuing student volunteers, or not having the capacity to supervise. These perceptions were found to be nuanced. Erroneous myths were seen to develop from a single event, later confirmed by a 'related' event; in scenarios with multiple players, motivations, and complexities. The potential for misconceptions to undermine the true value of student volunteering for all stakeholders is ameliorated when there is common
\end{abstract}

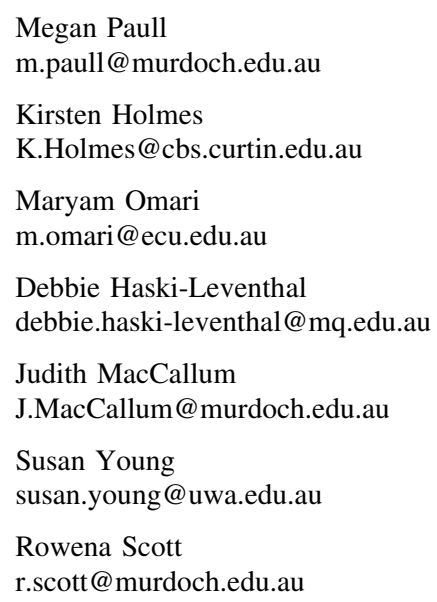

understanding, clear expectation setting, and ongoing dialogue.

Keywords Myths · Misconceptions - Sensemaking · Student volunteering $\cdot$ Host organisations $\cdot$ Volunteer management

\section{Introduction}

This paper reports on a heretofore largely unexplored topic of how erroneous myths and misconceptions can undermine the potential and value of university student volunteering. The overarching study of university student volunteering in Australia sought to explore the experiences of students, host organisations and universities participating in volunteering, to discover barriers to success and identify good practice from the perspectives of stakeholders in a range of settings. Myths and misconceptions

1 Murdoch Business School, Murdoch University, Perth, WA, Australia

2 School of Marketing, Faculty of Business and Law, Curtin University, Bentley, WA, Australia

3 School of Business and Law, Edith Cowan University, Joondalup, WA, Australia

4 Macquarie Business School, Macquarie University, Sydney, NSW, Australia

5 College of Science, Health, Engineering and Education, Murdoch University, Perth, WA, Australia

6 Social Work and Social Policy, University of Western Australia, Crawley, WA, Australia 
became the focus of an emergent research question and were identified as important potential barriers to success. This paper examines myths and developing myths about university student volunteering, considers their development and perpetuation, and identifies potential steps to their reduction based on data collected for the larger project, including stories from all stakeholders about their experiences.

In organisational settings, stories, not necessarily founded in fact, are used to explain or understand the world. Repeated stories become woven into the fabric of an organisation, are used in developing understanding, and are powerful in shaping behaviour (Gabriel, 1991). Bolman and Deal (2017) identify that myths and stories offer explanation and legitimation, adding to cohesion and mediating contradictions in turn providing the narrative of the organisation and its culture. Stories are capable of providing substance to the development and evolution of organisational culture, as well as offering researchers the opportunity to capture key data on interactions in organisations (e.g. Dailey \& Browning, 2014; Maclean et al., 2012; Martin, 2016; Yost et al., 2015). Stories can also be the basis for unhelpful stereotypes (Lyons et al., 2015; Riggio \& Saggi, 2015), creating and sustaining beliefs about individuals or groups (Bradley et al., 2000). Stories are retrospective, part of the sensemaking process (Weick et al., 2005), and contain individual interpretations, based on their view of the world. Repetition of stories, while useful in the transmission of knowledge and powerful in interpretation, can also serve to justify actions, rationalise outcomes, allow 'shaping' of understanding (Dailey \& Browning, 2014; Weick, 2012) and potentially even serve to subvert, manipulate, challenge, create dissent, and alienate (Beigi et al., 2019). (Mis)understandings and (mis)interpretations lead to the development of erroneous myths or misconceptions, which then influence behaviour, and efforts to dispel such myths can be harder than 'slaying dragons' (Gabriel, 1991, p. 427).

\section{Mythmaking}

Individuals, groups and organisations engage with stories to make sense of uncertainty or discomfort. Sensemaking (Weick, 1995) happens constantly, retrospectively, (often) subconsciously and is grounded in individual understandings of the world. In groups and organisations, shared sensemaking creates mutual understanding by developing a common narrative. Explanatory stories need to be plausible, and fit with existing understandings and shared assumptions. Sensemaking is heightened, becoming incipient, when a trigger or prompt, an interruption, causes 'what is happening here' and 'what action is needed' thinking. Triggers come from anything which does not quite fit or does not meet expectations. Stories which seem to 'make sense' are likely to appease discomfort and be accepted as reality. Stories can, however, be the basis of erroneous myths, particularly if perpetuated by repetition (see also Weick et al., 2005).

Once a story is accepted in a group or organisation, it can become embedded. Embedded stories become norms, influencing decision-making and behaviour, increasing in plausibility as the practices they influence become pervasive and self-perpetuating. The norms and assumptions on which decisions and behaviour are based become self-reinforcing, especially when individuals with influence appear to accept them. It is such self-reinforcing behaviour, which authors such as Tucker and Edmondson (2003) have long advised managers to question to prevent the perpetuation of errors in judgement based on myths or erroneous assumptions. As identified by Boje and et al., (1982, p. 18), organisations engage in mythmaking, as 'an adaptive mechanism.... to attribute meaning to activities and events.... [becoming] the basis for legitimising present and future behaviours'.

Attribution of meaning to activities and behaviours in organisations is a reinforcing and positive step, unless their basis is flawed. Contributors to erroneous assumptions are likely to be implicit bias and categorical thinking. Implicit bias (e.g. Gawronski \& Bodhenhausen, 2017; Noon, 2018) is said to arise from unconscious thinking based on attitudes and beliefs of which we may be unaware. Categorical thinking, conceiving people as being part of a social category or group, is one of the processes by which the brain organises complex knowledge, and has functional value in assisting employment of that knowledge, particularly in social processes (Liberman et al., 2017). Both of these can lead to our accepting an explanation, or story, because it fits with what we already 'know', even if the explanation or story is not grounded in fact.

Context contributes to what we already 'know', with stories being framed by where they are articulated (Van Hulst \& Ybema, 2020). Gabriel (1991, p. 430) argued that 'myths and stories are undoubted respositories of meaning' but are 'contorted and ambiguous' and should always be considered in the context in which they were generated. Context includes organisations where shared understandings, including misunderstandings and myths, become part of the culture (Bolman \& Deal, 2017) and can contribute to individual understanding, and shared understanding, and consequently to (flawed) decision-making.

There are many forms of volunteering. University student volunteering is one example where the inclusion of three parties (student volunteers, host organisations and universities) provides an opportunity to examine the development and perpetuation of erroneous myths from multiple perspectives. With the focus of our study being on 
identifying good practice, and barriers to success, erroneous myths and misconceptions presented one opportunity for improved practice.

\section{University Student Volunteering}

Volunteering by university students is an activity growing in prevalence and diversifying in form with one goal being enhancement of graduate employability (e.g. Williamson et al., 2018). Australian universities, similar to overseas counterparts, are increasingly evaluated on graduate employment outcomes (e.g. QILT, 2020). There are pressures to prepare students for post-graduation work. Student volunteering and related activities are part of a suite collectively known as work integrated learning (WIL), which has burgeoned in recent times (Jackson, 2017; Williamson et al., 2018). Service learning, a particular variation of student volunteering, includes the addition of reflective practice to embed learning while undertaking service to the community (Motoike, 2017; Thomson et al., 2011).

Organisations host student volunteers for a range of reasons, including diversifying their volunteer base and boosting volunteer numbers (Gazley et al., 2013). The contribution of these organisations to learning-related activities for students, providing a range of 'real-world' experiences to enhance graduate employment prospects, is often part of a wider community agenda (Motoike, 2017). Clarity about the relationships between students, their universities and host organisations is essential if the aims of student volunteering programs are to be achieved. Myths about university student volunteers can affect organisations' willingness to involve student volunteers, and the activities in which they are willing to include them, potentially reducing opportunities for student volunteering.

The range of activities referred to as 'student volunteering' by Australia's universities include service learning and community participation (Paull et al., 2015). These activities vary across institutions with process and structural differences influencing the connection between students and host organisations. Varying levels of experience within universities and among host organisations also contribute to the student volunteer experience (Paull et al., 2017).

Research on student volunteering worldwide has often focused on the student experience, with the host organisation perspective somewhat overlooked. The US research investigating service learning identified the importance of the host organisation in offering a positive experience (Gazley et al., 2013; Littlepage et al., 2012). Elements found to be central to success are: being organised and prepared to host students (Gazley et al., 2013; Worrall, 2007), good relationships, good communication and processes (Edwards et al., 2001; Littlepage et al., 2012); and appropriateness of students' skills and attitudes (Gazley et al., 2013). Complexities associated with hosting student volunteers have been identified, and include issues common to a range of volunteering contexts (e.g. Lough \& Carter-Black, 2015; Lyons et al., 2012) such as considering the impact of volunteer activity on beneficiaries and organisations (Edwards et al., 2001; Tiessen \& Heron, 2012).

The analysis which follows is based on the emergent research question examining myths and misconceptions. The analysis considers their origin, evolution, transmission, and perpetuation, and the contradictory evidence which emerged from the study, and considers some options for dispelling or ameliorating their impact.

\section{Method and Approach}

A qualitative interpretivist study was considered appropriate to allow for inclusion of multiple voices, and both inductive and deductive analysis (Creswell, 2013) of the experiences of stakeholders in university student volunteering. Interpretivism offers the opportunity for the researchers to interpret [people's] actions and their social world from their point of view'(Bryman \& Bell, 2015, p. 30). Following human research ethics committee approval, ${ }^{1}$ a modified theoretical sampling method (Birks \& Mills, 2011) was applied, and an extensive suite of sixtyone semi-structured interviews was undertaken with student volunteers, university staff, and experienced host organisation representatives, including from a peak body in Australia. Initial recruiting took place via universities and the peak volunteering body by purposefully approaching individuals involved with university student volunteering programs using snowball sampling to identify further interviewees 'likely to know' (Bryman \& Bell, 2015, p. 651) about university student volunteering. In total 19 students, 25 university representatives and 17 nonprofit organisation representatives were interviewed.

Participating host organisations included: community organisations who involve student volunteers; organisations operating across a number of universities, both student-led and independently organised (e.g. indigenous mentoring organisations, youth organisations); and studentled campus-based organisations (e.g. photography club, sustainability garden group). Universities also involve student volunteers directly in activities such as open days and thus their representatives also had some host perspectives to offer.

\footnotetext{
${ }^{1}$ Human Research Ethics Committee approval was granted at the lead institution and reciprocal approval at the institutions of all partner researchers.
} 
Data were collected via semi-structured interviews (Alvesson \& Ashcraft, 2012) conducted by the research team. Interviewees were encouraged to talk expansively about their experience, perspectives and opinions on everything from benefits and challenges of university student volunteering to processes of organising, policy development and decision-making. The interview protocol was consistent across all interviews 'to ensure a modicum of comparability' (Bryman \& Bell, 2015, p. 484), framed to capture the perspective of the different stakeholders, and to allow interviewers to probe complex answers. All interviews were recorded and transcribed with the informed consent of participants, with transcripts de-identified for analysis.

Three stages of data analysis included: within-case analysis for each university, cross-case analysis (Eisenhardt, 1989), and then analysis by interviewee type (student, host, and university). A general method of comparative analysis was undertaken by the research team in an iterative manner individually, and then at a group level to ensure consistency, to ground the analysis in the data (Birks \& Mills, 2011). The processes of coding included the development of initial codes followed by the identification of both saturated and emergent categories (Miles et al., 2014), and cross-researcher comparisons were undertaken to ensure consistency and agreement between team members (Charmaz, 2008).

Representative quotes were retained for themes in saturated categories, including contradictions (Charmaz, 2008; Miles et al., 2014). Contradictory themes and findings aided in the identification of concerns and misconceptions about student volunteering. Bottom up coding led to the emergent question as to whether there were erroneous myths about student volunteering, which were undermining the potential for success in some circumstances. Top down coding, once this issue was identified, led to the conclusion that there was of a series of myths and misconceptions identified as in place or developing. The research team then examined their formation, evolution and perpetuation, and possibilities for amelioration. Member checks (Thomas, 2017) were undertaken via participant feedback workshops. Participant feedback workshops were carried out by the research team. They involved a series of workshops with participants who had been involved in the original research (member checks), and with broader stakeholders across Australia with an interest in University Student Volunteering. Over 200 people were involved in these workshops, which were interactive sessions to explore our findings and refine our thinking. The richness of the feedback enabled good discussion about all aspects of the project, including myths and misconceptions and the research team's understanding of these. The interpretation as to whether a myth or misconception was in place, or still developing, was based on both experiences of participants who had been subject to the outcomes of decisions, and on the reports of those who had witnessed these outcomes or been involved in discussions about university student volunteers.

\section{Findings}

The research uncovered a range of perceptions about university student volunteering which were broadly understood but at the same time more complex than initially appeared. In addition, the data revealed some myths, which had developed over time or were currently developing and which, if left unchecked, could lead to unhelpful decision making. This section sets out the broad understandings, followed by the myths and developing myths, supported by quotes from interviews.

University students were perceived by some host organisations as having flexible time, the energy of youth, and a level of skill associated with undertaking university study. This perception, while having some veracity, was found to contain some more nuanced elements needing consideration.

First, university student volunteers cannot be considered a homogenous group, even in the way they connect to volunteering. Three broad types of student volunteer were identified and categorised in the data. Independent student volunteers were identified as self-organising, giving time independently of university programs. Their volunteering is not always associated with their area of study. Facilitated student volunteers were identified as those whose volunteer activity was a result of a mediated relationship between the university (or student body or other agent) and the program or host organisation. Academic student volunteers were identified as undertaking some form of assessable or monitored volunteering associated with their studies, including for this discussion, service learning.

Next, diversity of student volunteers was found to extend to personal characteristics, which influence the student and host experience. Student volunteers are not all of school-leaver age, with the demographics of Australian university students being reflected among those who volunteer. In 2019 (and pre COVID 19), Universities Australia (2019) reported that only $60.9 \%$ of higher education students are under 25 years of age, with $39.1 \%$ being older. Further, many students are working while studying, including many in casual employment to fund their studies. These factors restrict time availability of students for volunteering. Student profiles across the participating organisations further illustrated the diversity of Australian university students. The typical student at one of the universities studied, for example, is a 26-year-old female, 
studying part-time. This often means that the student has carer responsibilities for children or other family members, and work commitments to juggle. This diversity was reflected in the university student volunteering body, with those involved squeezing their volunteering into already busy schedules which included study, work and family commitments. The notion that student volunteers are young, time abundant, energetic and skilled is inaccurate.

The third element of student volunteer diversity is capability. Students volunteer in areas both related and unrelated to their studies, and at varying stages in their courses, thus their skill development is diverse. Reported reasons for volunteering included to gain exposure to organisational types; or to practice skills associated with their degree, and, for some international and culturally and linguistically diverse (CALD) students, to improve their English language skills. Alternatively, student volunteers may be seeking experiences outside their studies, to make friends or enjoy a social life. They come to volunteering with differing motivations and varied levels of skill and experience thus requiring screening, matching and placement processes like all volunteers.

Host organisations were found to involve some or all of the types of student volunteers. The range of activities offered was broad, including human services, conservation, sport, cultural and educational volunteering such as mentoring of primary school students. Students were found to be involved in many different forms of volunteering from traditional activities through to short term and episodic volunteering, with some involved in multiple forms of volunteering. The approach to hosting student volunteers varied between organisations, with differences including responsibility for supervision, allocation of tasks, and relationship to mainstream volunteer programs. Specific bespoke student volunteer programs were found in some host organisations, in student-driven organisations, and in university programs. Specialist programs ranged from those designed to fit student timetables, to some catering for specific student outcomes such as career development.

The benefits derived from hosting student volunteers were evident in the enthusiasm of host organisation representatives who spoke about the students' enjoyment, and demonstrated commitment to longevity of student involvement in their programs. Host organisation accounts, however, were not always grounded in specific events, with evidence that erroneous myths about student volunteering had emerged. Erroneous myths can underpin misjudgement and poor decision-making, and have a deleterious effect on student volunteers and host organisations, including having organisations decline to host student volunteers. It is important to identify how myths originate and consider options for preventing, minimising or dispelling them if we are to ameliorate their effects and create successful programs.

Contradictions emerged from the data that led to identification of a range of stories or characterisations associated with university student volunteering, which had influenced subsequent behaviour and produced negative outcomes. Some of the stories or characterisations appeared to have contributed to the development of erroneous myths or misconceptions about student volunteering. Undesirable outcomes included students choosing to discontinue volunteering, or organisations deciding to no longer host students. What follows is an exploration of some myths and misconceptions, which emerged from the data, followed by a broader discussion of the evidence, and potential implications. Two categories of data are discussed: Myths and Developing Myths. The former refers to narratives or stories erroneous in their substance but which were heard sufficiently often across multiple interview types to cause concern as a repetition of an erroneous myth, and on which there was evidence of decisions having been made. The latter are seen as nascent in their development with insufficient repetition to yet be labelled a myth, but repeated sufficiently often to cause concern as having the potential to develop into an erroneous myth. In the case of developing myths, there was evidence of the emergent thinking being considered but still not embedded. It was the identification of these two categories, which contributed to an understanding of the evolution or development of myths discussed later.

\section{Myth-Students are Unreliable}

One host organisation representative highlighted a view, also reported in interviews with others, including university representatives-that students are unreliable. This view was not universal, but was repeated enough to cause concern. The data were interrogated for evidence about students' reliability. Evidence of what might be interpreted as 'unreliability' included student volunteers who failed to attend rostered activities, students who changed rostered activities 'at the last minute', and students who 'faded away', or gradually stopped volunteering despite voicing longer-term commitment.

Triangulation of data led to conclusions that the first two factors were often related to study commitments and assessments. The third seemed to result from timetable changes, graduation or changed responsibilities, including paid work and family obligations:

exam time came and it was crisis point, can't deal, can't stay on, whatever and it left us in really quite a difficult position in our volunteer program (Host organisation representative). 
Even the host organisation interviewee most strident about student reliability stated that study commitments should take priority over volunteering. Despite acknowledging the importance of studying, organisations had identified this as a challenge large enough for them to change their programs:

we actually changed our recruitment to thinking that students were no longer our target [volunteer] group and that's enormously disappointing to me but we felt very disappointed in the general approach by students (Host organisation representative).

Other interviewees identified that structuring volunteering activity to be short term, or include flexibility to incorporate study commitments was the key to combatting student unreliability:

We kept the six week program to a short program ... with most uni students ... working three or four jobs ... plus you come across some students that are looking after their elderly parents themselves or family members, so keeping it to a short program is easy for them to commit to (Host organisation representative).

Organisations indicated they sought verbal commitment from students:

we really would like you to give us some sort of commitment $\ldots$ because it's this type of role and if people just pull out willy-nilly this is the consequence for us (Host organisation representative).

Interviews revealed that students cannot always foreshadow the impact that study and other commitments will have on their capacity to volunteer. Some students made commitments they were unable to keep, with student interviewees mentioning prioritising studying and paid work over volunteering. Paid work, especially on-call and casual work, undertaken to finance studying, meant that pre-planned volunteering was abandoned for paid work. Recognition from the host organisation that students may not have the capacity to predict what study, paid work and other life commitments might involve, and that balancing these was part of the learning process for the students, emerged as precursors to avoiding 'unreliability'. Assisting students to prioritise paid work or university assignments over volunteer commitments where necessary, and enabling them to, for example, swap volunteer rostering arrangements with other volunteers, was one option some host organisation representatives identified. Stories, or myths, of 'unreliability' may have included specific elements associated with being a student, but were not, according to some organisational representatives, confined to students.

\section{Myth-Students are Hard Work}

Some volunteer managers classify students as a discrete cohort, leading to closer scrutiny of arrangements. One manager observed: 'we've had some experiences that have not been satisfactory... we felt very disappointed in the general approach by students', describing how her organisation invested a lot of time in training and supervising student volunteers to ensure attendance, compliance with organisational requirements and meet client needs, only to find that students needed greater supervision than other volunteers. She elaborated: 'because we're not sure that we've got a good understanding yet of how students want to be involved and do we have the right conditions and roles for students...' indicating that somehow students are different to other potential volunteers. Another manager indicated that at times they have to meet with student volunteers who were not performing their role in the way which was expected by the organisation, including being unreliable as discussed above: 'The student comes to me here, and they know, because they come up with their head down', commenting on her time and that of the staff who have referred the student volunteer back for that performance meeting.

The notion that managing students is harder work than managing other volunteers is multilayered with the data indicating potential contributors to this perception. Universities may contribute to the perception of students being difficult during the facilitation of relationships with host organisations by seeking to have written agreements, by stipulating performance requirements, or by asking host organisations to report back on student performance.

Interview data revealed approaches to managing student requirements, which are easy to implement, and potentially relevant to all volunteers. One host organisation, for example, implemented a 'try before you commit' approach:

So ... they start and they see how they go three times before we kind of carry on with them. Some we've had to refuse, and it happens - some we've had said 'no not suitable', or not interacting [with clients] or fell asleep or checking on their phone (Host organisation representative).

The opportunity for a student volunteer to recognise that they were not suited to the work was also valued:

... the reality is if you are doing something that you want to do in the future, and there's interacting with the younger people or older people with disabilities, and you're not interacting in this environment, then you're not going to [succeed] ...., so you really need 
to change your course and have a think of something else. (Host organisation representative).

This host organisation interviewee saw the benefits to the organisation, to the student and to future potential employers in this opportunity for a student to decide they were not suited.

\section{Myth-Hosts Don't Have the Skills or Time to Supervise}

One university representative articulated a shared view that 'hosts don't have the skills or time to supervise':

They [students]'re given tasks that the organisation can't do themselves. They [hosts] can't monitor them properly and they can't advise them or mentor them really well because they don't have those skills so the students are dumped in the deep-end (University representative).

Potentially this developed from misunderstandings about the skills students bring to an organisation. Hosts may take on students to assist with areas where they cannot undertake the work themselves, in the unspoken expectation (rather than expressed wish) that students have sufficient skills for the assigned activity. There was some indication that hosts expected student volunteers to receive support and guidance from specialist university staff. Sometimes this was the case, and there is potential for this type of hosting to increase as changing funding models for nonprofit organisations prompt them to seek out expert services. Alternatively, universities may be placing students in organisations anticipating (rather than expressing) that host organisations will be able to expose them to expert staff or volunteers. The evidence is that there are some opportunities for students with nascent skills to volunteer with skilled mentors in host organisations:

[we offer] exposure to a highly professional marketing team, for example our fundraising and national events team and there's a whole lot going on there, [and] our donor and bequests team. So there's exposure for a student to a whole range of things that will certainly add to their skills base but it also adds to their development as a person (Host organisation representative).

Interviewees also identified situations where skilled students undertake work to practice these skills with support from university staff. The evidence showed that the perception of inadequate host supervision can have its genesis when the locus of expertise is not clearly articulated. All parties need to know what expertise is expected from whom; this also applies to volunteers other than student volunteers.

\section{Developing Myth-Hosts Don't Always 'Value' Student Volunteers}

Interview data revealed a view that organisations do not always value student volunteers. One example of this was a group of students recruited to assist with an event who found themselves 'standing around' for long periods of time leading to dissatisfaction. A university representative liaison with the host organisation reported 'some volunteers ... felt like they were just waiting around for things to get cranked up'. The university representative's assessment was that the organisation had recruited students without clear activity planning. He expressed concerns about the reasons host organisations were recruiting students: perhaps that organisation was seeking to please the university by offering volunteering opportunities.

A representative from another university similarly expressed the view that some host organisations take on student volunteers to accommodate the university or the students, not because there was work to be done. She referred to an 'oversupply' of students, and trying to maintain positions for student volunteers. This led to students being given 'the most boring tasks', and not 'being involved in any projects'. In some cases, she speculated, this might be due to the Chief Executive Officer agreeing to hosting students, with the supervisor not being sufficiently interested to provide valuable tasks. The problem identified was that the rationale for hosting student volunteers were interpreted as being self-serving or unclear.

There was evidence that some volunteer activity assigned was below the skill level expected by students and perceived as boring. This reduced engagement, also reducing motivation to continue to volunteer, especially where students sought to enhance their employability. As with all volunteers, if students do not feel valued, they will become disillusioned, potentially leading to disillusionment with volunteering in general, and a reluctance to volunteer in the future.

\section{Developing Myth-Students Need to 'Hide' Instrumental Motives}

A further developing myth was one which could be working either way between students and organisations. Some students identified that part of their motivation for volunteering was to increase their employability, but felt they needed to hide this because organisations may not take them on. This concern was voiced by both students and university representatives. Some student volunteers whose initial motivation was employability reported that their 
experience had changed their thinking about volunteering. Individuals' reasons for volunteering are known to change over time (Cady et al., 2018), and students in this study indicated surprise (and pleasure) at the commitment they developed towards volunteering. Some of the hosts, who had witnessed the changes in student commitment, expressed the view that students should be open about their instrumental motivation for volunteering. One host offered the example of a student who she encouraged to change his thinking about saying he wanted to learn new skills:

The young lad yesterday, he said 'When I first applied I didn't think I could say that I wanted to add value to my career and learn new skills' and I said 'You know, that's so legitimate. We absolutely accept that people, particularly students, want to do that and we encourage it'. (Host organisation representative).

This host representative indicated that students should not conceal that they are motivated by including volunteer service on their curriculum vitae (CV):

So my expectation is that they ... say 'I want to do this and this is the reason that I would like to do it. I'm genuinely interested in your organisation but I'm interested in the benefits for me but I'm interested in giving some time and skills to the organisation. I want to develop new skills' (Host organisation representative).

The two way element of this developing myth is that some host organisations would rather not take on volunteers who do not have a commitment to the mission of the organisation. The host representative above was indicating that students should be genuinely interested in her organisation:

So I guess there's that fear that gosh I really want this to add value to my $\mathrm{CV}$ or my degree course or whatever, but if I tell them ... I might not be able to do it. (Host organisation representative).

While this may be a reasonable expectation, the data also revealed that many students knew little about the host organisation when they commenced volunteering, and that volunteering educated them about the organisation and its community. Other host organisations saw the opportunity to increase student awareness of their cause as part of hosting.

Concealment of the motive of CV building was revealed by interviewees as likely to lead to negative outcomes. Students committed to an organisation's mission are more likely to be prepared to take on all tasks allocated to them if they can see how they lead to the mission. Those not focussed on the mission are more likely to be disappointed if they are given routine tasks which they do not see as building their skills or knowledge. Conversely, hosts who turn away students who are open about wanting to build their CV may miss out on students who could develop a commitment to the organisation (staff, volunteers and clients). Some host organisations have embraced this aspect of student volunteering. They offer student volunteering activities specifically designed to assist with skill building, issue recognition letters or certificates acknowledging service and skills, and provide opportunities for students to articulate into other volunteer roles if they choose to continue to volunteer. One volunteer manager set aside time for individual feedback and counselling of student volunteers to ensure she can provide references. She also determined whether to invite students to continue to volunteer with the organisation beyond their student volunteering role.

\section{Discussion}

Our findings show that a series of myths have developed, or are potentially developing, around student volunteering. These myths involve student volunteers being perceived as unreliable and more difficult to manage compared to other cohorts. In contrast, universities partnering with host organisations to deliver student volunteer programs perceive some host organisations as unable to supervise students effectively and failing to value student volunteers. Further, students feel that they have hide their motives for volunteering. Our findings have revealed complexities in university student volunteering which, in part, can be attributed to the stories we tell about this activity.

The literature on sensemaking, mythmaking, meaning making, and storytelling (Bradley et al., 2000; Dailey \& Browning, 2014; Lyons et al., 2015; Maclean et al., 2012; Martin, 2016; Riggio \& Saggi, 2015; Weick et al., 2005; Yost et al., 2015) suggests that myths need to be countered by creating new understandings, by questioning underpinning assumptions and perspectives, and by limiting retelling of erroneous stories. Myths often emerge from actual events, even if only one, and the telling and retelling of the story can embellish and perpetuate them. It is important to identify not only their existence but also how they can be avoided, dispelled, countered, managed or minimised when they are erroneous and could lead to flawed decision making. Recognition of the manner of myth formation, which leads to misunderstanding is likely to go some way to alleviating negative outcomes.

Examination of each of the myths and developing myths identified in the data led to a number of observations. Notions that university students are young, time-flexible and skilled, accompanied by events/issues, which have 
arisen from recruiting students based on these assumptions, have contributed to the myths identified here. The myth that students are unreliable seems to arise from the notion that they are available, with time to volunteer, and from actions of a small number of students who fail to turn up, turn up late, or withdraw from their volunteering when other commitments take up too much time. Perhaps volunteer involving organisations are unfamiliar with the diversity of the contemporary student cohort, including an increasing proportion of mature students, studying part time and juggling family, work and study commitments (Universities Australia, 2019). The myth that students are hard work arises from organisational hope that students bring skills or expertise associated with their studies. This expectation combined with the needs that all volunteers have- to be oriented, inducted, supervised, trained and managed (Brudney \& Meijs, 2009; Rochester et al., 2010) — created a perception that student volunteers are harder work. The level of work associated with involving student volunteers may potentially be more than other volunteers, but the return on investment of time can yield good outcomes. Good communication, clear expectations and ongoing engagement are all hallmarks of quality volunteer management (Traeger \& Alfes, 2019) to which all volunteers are entitled.

The origins of developing myths - that hosts take on students without valuing them, and students who volunteer to increase employability need to conceal their motivation-may be grounded in unclear communication (Edwards et al., 2001). Activities which do not turn out as expected lead to attempts to explain or interpret what has happened-sensemaking. Sensemaking, and seeking plausible explanations for unexpected events or interruptions, when it takes the form of a narrative or story, is reinforced when another event confirms the explanation. Possibilities for countering myths are now examined in the context of this study.

Myths are most difficult to counter when there is evidence which appears to confirm them, even when there are contrasting stories being told. Myths become entrenched when not only are they confirmed, but they become embedded in systems, behaviours and thinking across the organisation (Bolman \& Deal, 2017). Our findings showed that these myths and developing myths about university student volunteering were based on some limited experiences. The development of these experiences into myths about student volunteering, however, risks undermining the value of this activity.

Merely presenting contradictory evidence is insufficient to dispel a myth (Moen et al., 2017). Evidence which challenges current systems and thinking needs to be compelling, and provide impetus for change in such a way as to allow assumptions and accepted 'truths' to be questioned.
The value of obtaining multiple views on the same issue has been apparent in this study where it was possible to see the perspectives of the different stakeholders; 'who' perpetuates the myth becomes important as it is often from a singular perspective.

The literature on dispelling myths shows that awarenessraising has long been identified as a process associated with cultural change and needs top-down support (Moen et al., 2017). Singling out a particular group for specific policies was found to be less effective than organisation-wide policies 'developing an institutional logic valuing all workers' (p. 7). Similarly, Ruiz Sportmann and Greenspan (2019) identified that fostering integration between different volunteers should be a goal. An institutional logic valuing all volunteers includes changing views about student as volunteers. Changing the narrative about university student volunteering is part of changing thinking and behaviour, including myths. To do this, four initial steps are proposed:

1. Educate participants (hosts, universities and students) on the diversity of university students to accurately frame engagement with university student volunteering:

2. Identify and call out myths, raising a challenge when sweeping statements are made without supporting evidence;

3. Question assumptions and interpretations of missteps and incidents, which may spawn or reinforce myths, and seek explanations which can be used to prevent such missteps and incidents being repeated; and

4. Ensure that stories of success and contribution become more prevalent in the narrative, providing evidence for new beliefs and attitudes which are more accurate.

In keeping with quality volunteer management approaches (Traeger \& Alfes, 2019), it is important to follow through with adopting management strategies and standards which benefit all volunteers. Suitable arrangements for communication, supervision, organisation and support are required for all volunteers (Brudney \& Meijs, 2009; Rochester et al., 2010).

Figure 1 illustrates how a single event or incident, which is later confirmed by a 'related' event, creates a storyline that evolves into an erroneous myth and leads to a change in practice. What follows is a discussion of a scenario using the example of university student volunteer 'unreliability' to illustrate the evolution of a myth, and possible interventions. The selection of the single erroneous myth as an example provides the opportunity to explain the evolutionary process.

At commencement there is no myth, when a student volunteer misses an important commitment. While the reason is unknown an organisational member concludes 
that this is due to study commitments, a plausible explanation, although unverified. This story or explanation is repeated, and becomes accepted: emerging myth. Another student volunteer then misses a less important commitment, but they are a 'student volunteer' and the two events become accepted as typical of student volunteer behaviour and the previously heard story of study commitments becomes part of the story: developing myth. The

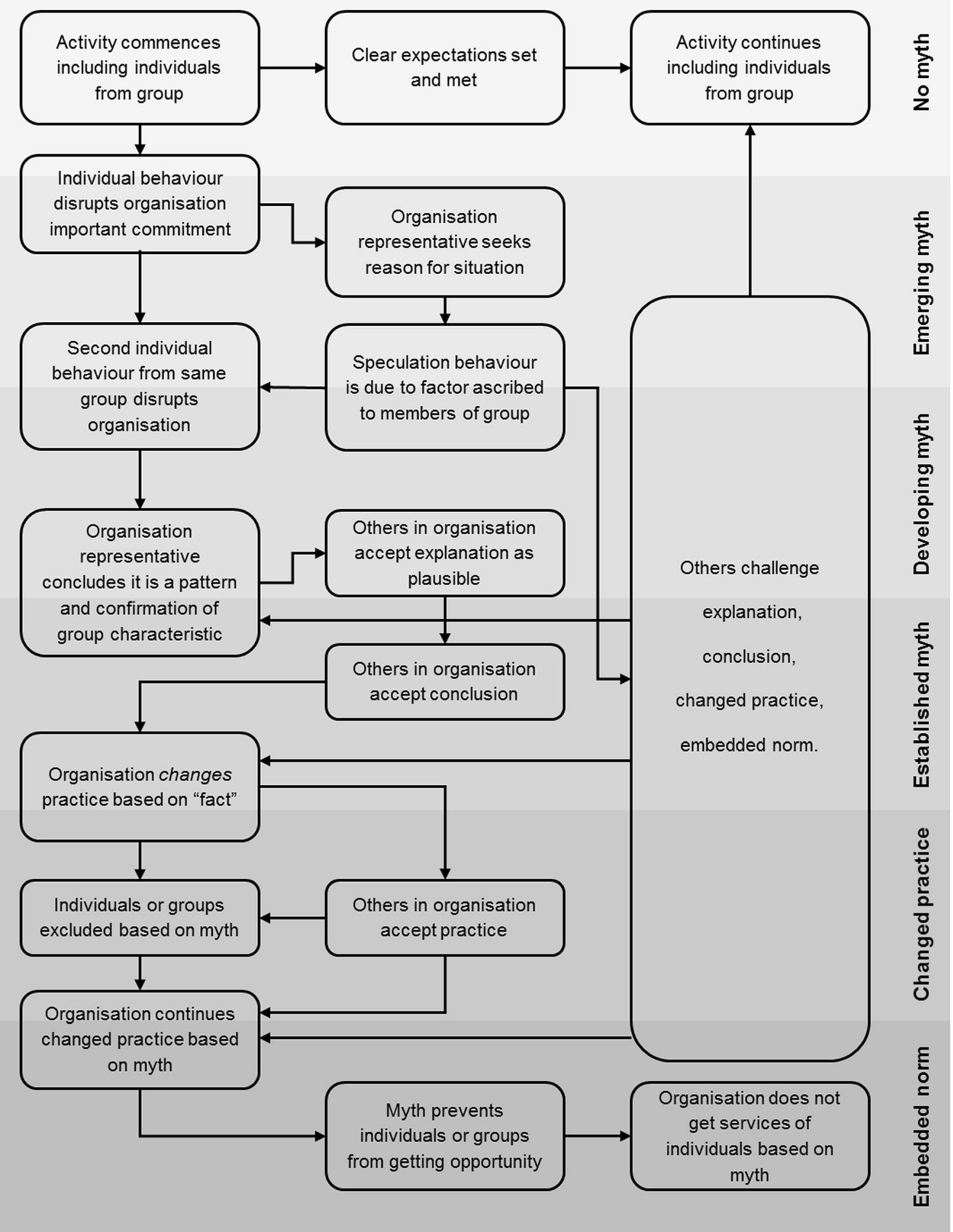

Fig. 1 Mythmaking and challenges to mythmaking 
source of the story adds weight to its veracity. The unreliability of student volunteers becomes accepted, even though it evolved from just two cases, and from unverified explanations. The sensemaking of the organisational representative created a plausible explanation. This explanation, passed on unchallenged, with the label 'student volunteer', including the reasoning around study commitments, becomes an established myth: 'students are unreliable'. This mythical explanation leads to changed practice, where the 'solution' to the 'problem' of student unreliability is that students should only be offered volunteering opportunities, which do not involve important or long-term commitments. Thus an embedded norm denies the students and the organisation future volunteering opportunities.

Different outcomes are possible where the narrative of 'unreliability' is challenged. Challenges prevent the 'solution' being to stereotype all student volunteers based on previous events, and thus separate them from mainstream volunteering. These may come at numerous points along the trajectory of the narrative. Challenges may require evidence that the majority of students are not behaving this way, and of the limited fallout from the actions of the second student. Evidence of the reasons for the students' missed commitments may also be needed. Most organisations in our study experienced situations where students missed commitments, but not all opined that students are unreliable, and some openly contradicted this-particularly the peak body representative interviewed. Importantly, where practice has evolved based on a myth, challenges to assumptions and practice led to a reconsideration of practice, and of the narrative. In this scenario, it is not too late to challenge practice or embedded myths, and while addressing issues which led to the development of the myth, a new approach is adopted.

Drawing on the perspectives of multiple stakeholders, student volunteers, host organisation representatives and university representatives, our study sought to identify good practice in university student volunteering and discover barriers to success. Discerning the emergence of myths in the data, and their potential as barriers to success, led to an examination of myths in this context. Combining the extant literature on workplace myths with work on narratives and storytelling, this paper provides explanations for some myths identified as being present or developing in university student volunteering. The evidence illustrates the way that a story or 'sense' of something accepted and embedded influences decision-making and behaviour. Stories, even when they are based in misconceptions or misperceptions, and their evolution into myths, are selfreinforcing when those with authority appear to accept them. This is then the basis for 'legitimising present and future behaviours' (Boje et al., 1982 p. 18). The evolution of myths, their influence on behaviours, which then serve to perpetuate them, led to the development of propositions to prevent, minimise or dispel myths.

These propositions, needing further exploration, add to knowledge about how we understand our world. Changing the narrative is part of the process of changing thinking and behaviour, including myths. There are some important steps, which we can take: calling out myths about volunteering; questioning assumptions and interpretations of missteps and incidents, which may spawn or reinforce myths; seeking explanations, which can be used to prevent such missteps and incidents being repeated; and ensuring that stories, which counter those myths become prevalent in the narrative are all possibilities along the way. It is important to follow through with strategies, which prevent or minimise the embedding of behaviours, and which allow myths to be spawned and perpetuated.

When it comes to student volunteering, the extant literature has tended to focus on the programs, motivations and outcomes (e.g. Holdsworth, 2010), rather than on nuanced management of student volunteers, the focus of this paper. The literature on managing volunteers has at its core the need for navigating the path between imposition of management practices developed for working with paid employees, the need for recognition of the voluntary status of volunteers, and the requirements of the organisation and the context of the volunteer activity (Brudney \& Sink, 2017). It has long been known that managing volunteers is complex (e.g. Meijs \& Ten Hoorn, 2008; Rochester et al., 2010), and we are still exploring the varied contexts in which volunteers engage, and the impact on volunteer outcomes (e.g. Morse et al., 2020).

The propositions outlined in this paper invite future research on myths in volunteering to further develop the notion that clear communication at the outset and throughout, or actions to question assumptions and change the narrative, which is forming, can serve to prevent the embedding of myths in organisations. Such research might include surveys of parties affected by myths in other volunteer settings and interviews with individuals who have been affected by decisions based on myths. In the case of university student volunteering there is the potential to further interview student volunteers, host organisations and university representatives who have taken action to prevent, divert or dispel myths, or to undertake an action research project to examine how interventions counter mythmaking. Clients or beneficiaries of student volunteering may also be a rich source of data to further develop this narrative.

The use of qualitative methods examining a small number of universities in Australia may mean that only moderatum generalisations may be made (Williams, 2002); however, the potential for myths about student volunteering to arise among each of the stakeholders and the need to 
address these is applicable widely. Student volunteering in locations outside Australia, where the context may vary, are likely to require investigation to add depth.

At the practical level, for erroneous myths to be dispelled, or to prevent spawning new myths, mechanisms for communicating and developing shared understanding are important. The process of coming to some agreement about each of the parties' expectations is likely to be central (Edwards et al., 2001). It is also necessary to establish ways of addressing those times when the behaviours of individuals indicate that a myth is being perpetuated, or might lead to creation of a new myth. In the example here, managers may need to consider alternative explanations for student unreliability. Students may need assistance to understand the implications of their behaviours for host organisations. University representatives are in a prime position to facilitate such discussions. As it is natural to seek plausible explanations for events or issues, which are not as intended or expected, it is unlikely that myths will disappear, but their impact may be lessened by recognition and re-evaluation.

\section{Conclusion}

This paper examines the origins, perpetuation and reduction of myths based on evidence from an Australian study of university student volunteering seeking to identify good practice. Employing an approach which obtained multiple stakeholder views, it illustrates the emergence of myths and posits that changing the narrative is part of changing thinking and behaviour, and seeks to contribute to the development of understanding about mythmaking. University student volunteering is an activity with multiple players, all approaching the arrangements with different frames of reference and motivations. Host organisations may see students as a potential source of labour, skills and energy. For universities, student volunteering is part of a suite of activities tied to graduate capability. Student volunteers have differing and wide ranging motivations for being involved.

In any scenario with multiple players and motivations, complexities arise. This study has unearthed some counterproductive myths around student volunteering, which have been perpetuated with tenuous links to practical realities. The full benefits for all parties can only be achieved when and if there is a common understanding, clear expectations, and on-going open dialogue-all elements of good practice in terms of managing volunteers. Consideration of the evolution, perpetuation and influence of myths, and subsequent behaviours has led to suggestions about preventing and countering them, which may apply in other settings and which may assist with dragon slaying (Gabriel, 1991).

Acknowledgements This research was conducted under the auspices of the Murdoch University Ethics Committee (HREC 2014/007) with reciprocal approval granted by all participating universities.

Funding This study was funded by the Australian Government Office for Learning and Teaching (Grant number ID 13-3124).

\section{Declarations}

Conflict of interest The authors declare that they have no conflict of interest.

\section{References}

Alvesson, M., \& Ashcraft, K. L. (2012). Interviews. Chapter 14. In Symon, G., \& Cassell, C. (Eds), Qualitative organizational research: Core methods and current challenges. Sage.

Beigi, M., Callahan, J., \& Michaelson, C. (2019). A critical plot twist: Changing characters and foreshadowing the future of organizational storytelling. International Journal of Management Reviews, 00, 1-19. https://doi.org/10.1111/ijmr.12203

Birks, M., \& Mills, J. (2011). Grounded theory: A practical guide. Sage Publications.

Boje, D. M., Fedor, D. B., \& Rowland, K. M. (1982). Myth making: A qualitative step in OD interventions. The Journal of Applied Behavioral Science, 18(1), 17-28.

Bolman, L. G., \& Deal, T. E. (2017). Reframing organizations: Artistry, choice, and leadership (6th ed.). John Wiley and Sons.

Bradley, H., Erickson, M., Stephenson, C., \& Williams, S. (2000). Myths at work. Polity.

Brudney, J. L., \& Sink, H. K. (2017). Volunteer management: It all depends. In Word, J. K. A., \& Sowa, J. E. (Eds.), The nonprofit human resource management handbook (pp. 204-222). Routledge.

Brudney, J. L., \& Meijs, L. C. (2009). It ain't natural: Toward a new (natural) resource conceptualization for volunteer management. Nonprofit and Voluntary Sector Quarterly, 38(4), 564-581.

Bryman, A., \& Bell, E. (2015). Business research methods (4th ed.). OUP.

Cady, S. H., Brodke, M., Kim, J. H., \& Shoup, Z. D. (2018). Volunteer motivation: A field study examining why some do more, while others do less. Journal of Community Psychology, 46(3), 281-292.

Charmaz, K. (2008). Grounded theory as an emergent method. In S. Hesse-Biber \& P. Leavy (Eds.), Handbook of emergent methods (pp. 155-172). Guilford Press.

Creswell, J. W. (2013). Research design: Qualitative, quantitative, and mixed methods approaches. Sage.

Dailey, S. L., \& Browning, L. (2014). Retelling stories in organizations: Understanding the functions of narrative repetition. Academy of Management Review, 39(1), 22-43.

Edwards, B., Mooney, L., \& Heald, C. (2001). Who is being served? The impact of student volunteering on local community organizations. Nonprofit and Voluntary Sector Quarterly, 30(3), 444-461.

Eisenhardt, K. M. (1989). Building theories from case study research. Academy of Management Review, 14(4), 532-550.

Gabriel, Y. (1991). On organisational stories and myths: Why it is easier to slay a dragon than to kill a myth. International Sociology, 6(4), 427-442. 
Gawronski, B., \& Bodenhausen, G. V. (2017). Beyond persons and situations: An Interactionist approach to understanding implicit bias. Psychological Inquiry, 28(4), 268-272.

Gazley, B., Bennett, T. A., \& Littlepage, L. (2013). Achieving the partnership principle in experiential learning-The non-profit perspective. Journal of Public Affairs Education, 19(3), 559-579.

Holdsworth, C. (2010). Why volunteer? Understanding motivations for student volunteering. British Journal of Educational Studies, 58(4), 421-437.

Holmes, K., Paull, M., Haski-Leventhal, D., MacCallum, J., Omari, M., Walker, G., Scott, R., Young, S., \& Maher, A. (2021). A continuum of university student volunteer program models. Journal of Higher Education Policy and Management., 43(3), 281-297.

Jackson, D. (2017). Developing pre-professional identity in undergraduates through work-integrated learning. Higher Education, $74,833-853$

Liberman, Z., Woodward, A. L., \& Kinzler, K. D. (2017). The origins of social categorization. Trends in Cognitive Sciences, 21(7), $556-568$.

Littlepage, L., Gazley, B., \& Bennett, T. A. (2012). Service learning from the supply side: Community capacity to engage students. Nonprofit Management and Leadership, 22(3), 305-320.

Lough, B. J., \& Carter-Black, J. (2015). Confronting the white elephant: International volunteering and racial (dis)advantage. Progress in Development Studies, 15(3), 207-220.

Lyons, K., Hanley, J., Wearing, S., \& Neil, J. (2012). Gap year volunteer tourism: Myths of global citizenship? Annals of Tourism Research, 39(1), 361-378.

Lyons, S., Urick, M., Kuron, L., \& Schweitzer, L. (2015). Generational differences in the workplace: There is complexity beyond the stereotypes. Industrial and Organizational Psychology, $8(03), 346-356$.

Maclean, M., Harvey, C., \& Chia, R. (2012). Sensemaking, storytelling and the legitimization of elite business careers. Human Relations, 65(1), 17-40.

Martin, S. R. (2016). Stories about values and valuable stories: A field experiment of the power of narratives to shape newcomers' actions. Academy of Management Journal, 59(5), 1707-1724.

Meijs, L. C. P. M., \& Ten Hoorn, E. (2008). No "one best" volunteer management and organizing: Two fundamentally different approaches. In Liao-Troth, M. (Ed.), Challenges in volunteer management (pp. 29-50). IAP.

Moen, P., Kojola, E., \& Schaefers, K. (2017). Organisational change around an older workforce. The Gerontologist, 57(5), 847-856.

Morse, J. L., Dik, B. J., Shimizu, A. B., \& Reed, K. A. (2020). Volunteerism and burnout: Does satisfaction of motives for volunteering protect against symptoms? VOLUNTAS: International Journal of Voluntary and Nonprofit Organizations. https:// doi.org/10.1007/s11266-020-00257-y.

Motoike, P. (2017). Service learning course construction and learning outcomes. In C. Dolgon, T. Mitchell, \& T. Eatman (Eds.), The Cambridge handbook of service learning and community engagement (pp. 132-146). Cambridge University Press.

Noon, M. (2018). Pointless diversity training: Unconscious bias, new racism and agency. Work, Employment and Society, 32(1), 198-209.

Paull, M., Omari, M., MacCallum, J., Young, S., Walker, G., Holmes, K., Haski-Leventhal, D., \& Scott, R. (2017). Matching expectations for successful university student volunteering. Education + Training, 59(2), 122-134.

Paull, M., Scott, R., MacCallum, J., Walker, G., Omari, M., Young, S., Haski-Leventhal, D., \& Holmes, K. (2015). University student volunteering: What's in a name? Third Sector Review, 21(2), 49-74.
QILT-Quality Indicators in Learning and Teaching. (2020). 2019 Employer satisfaction survey. Available https://www.qilt.edu.au/

Riggio, R. E., \& Saggi, K. (2015). Belief in generational stereotypes: Why there is a there there. Industrial and Organizational Psychology, 8(03), 340-342.

Rochester, C., Ellis Paine, A., \& Howlett, S. (2010). Volunteering and society in the 21st century. Palgrave Macmillan.

Ruiz Sportmann, A. S., \& Greenspan, I. (2019). Relational interactions between immigrant and native-born volunteers: Trustbuilding and integration or suspicion and conflict?. VOLUNTAS: International Journal of Voluntary and Nonprofit Organizations, 30(5), 932-946.

Thomas, D. (2017). Feedback from research participants: Are member checks useful in qualitative research? Qualitative Research in Psychology, 14(1), 23-41.

Thomson, A. M., Smith-Tolken, A. R., Naidoo, A. V., \& Bringle, R. G. (2011). Service learning and community engagement: A comparison of three national contexts. VOLUNTAS: International Journal of Voluntary and Nonprofit Organizations, 22(2), 214-237.

Tiessen, R., \& Heron, B. (2012). Volunteering in the developing world: The perceived impacts of Canadian youth. Development in Practice, 22(1), 44-56.

Traeger, C., \& Alfes, K. (2019). High-performance human resource practices and volunteer engagement: the role of empowerment and organizational identification. VOLUNTAS: International Journal of Voluntary and Nonprofit Organizations, 30(5), $1022-1035$

Tucker, A. L., \& Edmondson, A. C. (2003). Why hospitals don't learn from failures: Organizational and psychological dynamics that inhibit system change. California Management Review, 45(2), $55-72$.

Universities Australia. (2019). Data Snapshot 2019. Author. Available: https://www.universitiesaustralia.edu.au/australias-universi ties/key-facts-and-data\#.XMp0QBRLiUl.

van Hulst, M., \& Ybema, S. (2020). From what to where: A settingsensitive approach to organizational storytelling. Organization Studies, 41(3), 365-391.

Weick, K. E. (1995). Sensemaking in organizations. Sage.

Weick, K. E. (2012). Organized sensemaking: A commentary on processes of interpretive work. Human Relations, 65(1), 141-153.

Weick, K. E., Sutcliffe, K. M., \& Obstfeld, D. (2005). Organizing and the process of sensemaking. Organization Science, 16(4), 409-421.

Williams, M. (2002). Generalization in interpretive research. In May, T. (Ed.), Qualitative research in action. Sage. (pp. 125-143).

Williamson, I., Wildbur, D., Bell, K., Tanner, J., \& Matthews, H. (2018). Benefits to University students through volunteering in a health context: A new model. British Journal of Educational Studies, 66(3), 383-402.

Worrall, L. (2007). Asking the community: A case study of community partner perspectives. Michigan Journal of Cотmunity Service Learning, 14(1), 5-17.

Yost, P. R., Yoder, M. P., Chung, H. H., \& Voetmann, K. R. (2015). Narratives at work: Story arcs, themes, voice, and lessons that shape organizational life. Consulting Psychology Journal: Practice and Research, 67(3), 163.

Publisher's Note Springer Nature remains neutral with regard to jurisdictional claims in published maps and institutional affiliations. 